\title{
Toward a Resilient Network by Optimal Sizing of Large Scale PV Power Plant in Microgrid-Case Study of Mongolia
}

\author{
Sainbold Saranchimeg \\ Electrical and Computer Engineering \\ University of Auckland \\ Auckland, New Zealand \\ ssar783@aucklanduni.ac.nz
}

\author{
Mohammad Javad Sanjari \\ Electrical and Computer Engineering \\ University of Auckland \\ Auckland, New Zealand \\ msan310@aucklanduni.ac.nz
}

\author{
Nirmal K.C.Nair \\ Electrical and Computer Engineering \\ University of Auckland \\ Auckland, New Zealand \\ n.nair@auckland.ac.nz
}

\begin{abstract}
Competitive price and eco-friendly operation features make solar photovoltaic (PV) plant a strong candidate for a modern power system's generation mix. Therefore, it has been economically feasible to build PV based microgrids, which can convert current centralized national grids into decentralized segments so that resiliency of grid will improve and line loss will decrease. In this study, we examined integration scenarios of different size of PV plants into Altai Uliastai Energy System (AUES) of Mongolia in order to evaluate the possibility of developing microgrid using current hydropower plant (HPP) and proposed PV plant. Results showed that a PV plant with $10 \mathrm{MW}$ capacity would perform well with HPP and load from energy management point of view. DIGSilent Power Factory has been used for quasi-dynamic simulation.
\end{abstract}

Index Terms-Hydroelectric power generation, Microgrid, Mongolia, Photovoltaic system, Solar energy

\section{INTRODUCTION}

Nowadays, a rise in climate change rate and natural disasters occurrence imposes a need for more renewable-based and resilient power systems. Developing decentralized microgrids [1] by using renewable resources can bring not only a decrease in $\mathrm{CO} 2$ emission and line loss but also improvement of network resiliency. A competitive cost of photovoltaic (PV) panel, which is reducing day by day, makes it a plausible candidate for microgrid power sources. According to International renewable energy agency, a global installed capacity of PV has increased 45 times between 2007 and 2017. The lower price of PV made it cost effective as same as coal-fired plants so that large-scale PV plants attracted much attention from investors. In 2016, centralized PV systems occupied over $70 \%$ of the increase in installed capacity while decentralized systems occupied rest [2] as shown in Fig. 1.

Initially, microgrid concept was proposed in [3] for improvement of reliability of power systems and rural electrification [4]. Although the renewable energy sources are a good option for microgrid development [5], an intermittent nature of it causes problems during islanded operation so that energy storage and auxiliary generation are required for reliable operation of microgrid during that operation. The possible impacts of high penetration of $\mathrm{PV}$ plant have been studied in [6]-[10] in terms of technical and economical aspects.

Mongolia is a northeast Asian landlocked country, and it has huge solar potential because of vast territory and high sunshine duration [11]. As the Mongolian mining industry is in rapid growth, the government is willing to invest in sustainable development projects such as renewable generation. According to the amendment of state energy policy, the target is increasing the share of renewable energy in total installed capacity to $20 \%$ by 2023 and $30 \%$ by 2030 [12].
Solar PV Global Additions, Shares of Grid-Connected and Off-Grid Installations,
2006-2016

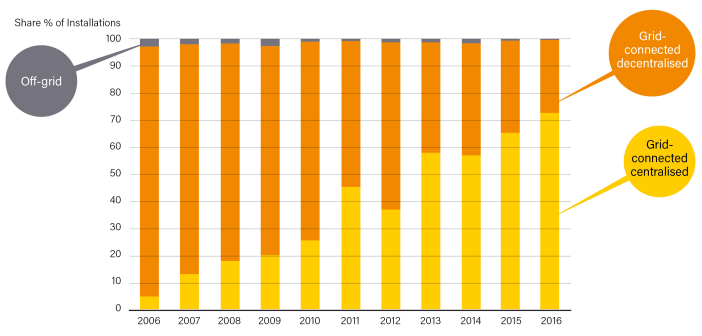

REN21 Renewables 2017 Global Status Report REN21 Source: IEA PVPS.
Fig. 1. A share of centralized and decentralized PV plants into total PV capacity increase in 2016

As of 2017, a total installed capacity of Mongolian power system is $1180.8 \mathrm{MW}$ and share of renewable generation is 120 MW excluding 23 MW hydropower capacity. Currently, two $10 \mathrm{MW}$ PV plants are in operation and three PV plants with a cumulative capacity of $40 \mathrm{MW}$ are under construction and are expected to be completed in 2018. Since population density is low, Mongolian cities are located far from each other. All the big cities are interconnected through high voltage overhead lines. Since a bulk generation is located in Ulaanbaatar which is the capital city and transmitted power 


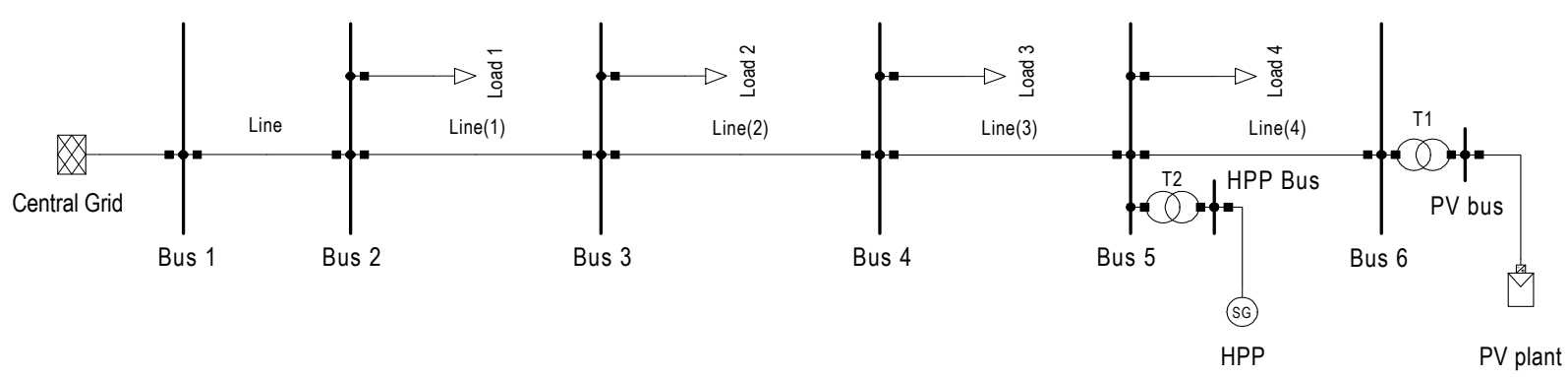

Fig. 2. Simplified high voltage model of AUES network.

throughout the country, the line loss of the system is high and resilience against natural disaster is low because single lines are connecting the cities to the central generation.

Based on the aforementioned features of the Mongolian power system, it is an effective option to develop microgrids in the cities to reduce $\mathrm{CO} 2$ emission and line loss and to increase the resilience of the national network. Some challenges for creating microgrid in Mongolian Western region were examined in [13]. Decentralized and local generation will also help to reduce upgrade cost of current infrastructure, which requires substantial investment.

In this paper, a possibility to create microgrid in Altai Uliastai Energy System (AUES) in Mongolia by adding PV plant was studied and the optimal size of PV plant was chosen using results of an energy generation profiles and the quasi-dynamic simulation. The result of the study could help to understand the influence of PV plant integration on AUES. In addition, generation profile of PV plant using measurement data could be used for a realisation of hybrid working scenarios of PV and existing hydropower plant (HPP).

\section{Methodology}

In this study, we have chosen the optimal capacity of the PV plant to create a microgrid in AUES of Mongolia using energy management prediction and quasi-dynamic load flow analysis. Firstly, generation profiles of PV plants with various capacities are evaluated using solar radiation measurement data. Global and beam radiation data measured in 2004-2012 on a horizontal surface in Altai city, Mongolia were used for the evaluation which is $50 \mathrm{~km}$ away from the PV plant area of interest. The radiation on a horizontal surface was converted into a tilted surface and then used in a parametric model for evaluation of PV generation. A load data of AUES of last twelve months were adopted from monthly reports of National Dispatching Center of Mongolia.

In order to estimate generation profiles of PV plants, the solar radiation on a horizontal surface was converted into a tilted surface using isotropic sky model [14]. The main equation for conversion is given as follows:

$$
I_{T}=I_{b} R_{b}+I_{d}\left(\frac{1+\cos \beta}{2}\right)+I \rho_{g}\left(\frac{1-\cos \beta}{2}\right)
$$

In the equation (1), $I_{T}$ is a radiation on the tilted surface, $I_{b}, I_{d}$ and $I$ are the beam, diffuse and global radiation on a horizontal surface, respectively. $\beta$-tilt angle, $\rho_{g}$-reflection coefficient of ground and $R_{b}$ is a ratio of the beam radiation on the tilted surface to that on a horizontal surface, which is calculated by the following expression:

$$
R_{b}=\frac{\int_{w_{1}}^{w_{2}} \cos \theta d w}{\int_{w_{1}}^{w_{2}} \cos \theta_{z} d w}
$$

where $\theta$ and $\theta_{z}$ are the incident angle on PV panel and horizontal surface, respectively. $w_{1}$ and $w_{2}$ are hour angles of two adjacent hours.

A power output of the PV plants is calculated using the equivalent circuit of a PV cell, which is shown in Fig. 3. An ideal equivalent circuit of PV cell is illustrated by a current source and a diode [15] (Fig. 3a). This circuit illustrates PV cell behavior well in high radiation condition. A circuit model has shown in Fig. 3b was proposed for more accurate modeling of PV cell in low radiation condition. By adding shunt resistance, PV module production in partially shaded condition could be predicted more accurately. Similarly, by adding series resistance to the model, bounding the contact resistance was considered in the calculation [16].

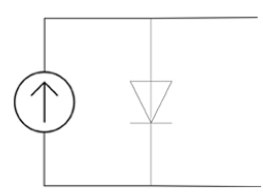

a)

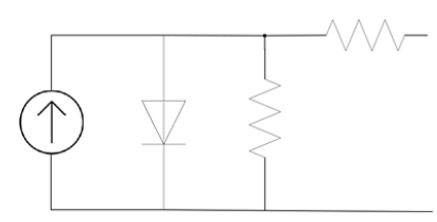

b)
Fig. 3. Equivalent circuits of PV cell

For single diode model with series and shunt resistance (Fig. $3 b$ ), the main equation of output current of a cell is expressed as follows:

$$
I=I_{p h}+I_{0}\left[\exp \left(\frac{V+I R_{s}}{a}\right)-1\right]-\frac{V+I R_{s}}{R_{s h}}
$$


where $I_{p h}$ is photocurrent which is generated by sunlight directly, $I_{0}$ is diode saturated current, $a$ is thermal voltage, $V$ is cell voltage, $R_{s}$ and $R_{s h}$ are series and shunt resistances respectively.

$$
a=\frac{N_{S} \times A \times k \times T_{c}}{q}
$$

where $N_{S}$ is number of elements connected in series, $A$ is cell ideality factor, $k$ is Boltzmann constant, $T_{c}$ is actual cell temperature and $q$ is electron charge. The photocurrent is given by

$$
I_{p h}=\frac{G}{G_{r e f}}\left(I_{p h . r e f}+K_{I} \Delta T\right)
$$

where $G$ is incident radiation on a cell, $G_{r e f}$ is radiation of standard test condition (STC), $I_{\text {ph.ref }}$ is photocurrent at STC, $K_{I}$ is short circuit current temperature coefficient and $\Delta T$ is the difference between actual cell temperature and STC temperature.

The diode saturation current is written as follows:

$$
\begin{aligned}
I_{0}= & I_{s c} \times \exp \left(\frac{-V_{o c}}{a}\right) \times\left(\frac{T_{c}}{T_{r e f}}\right)^{3} \\
& \times \exp \left[\left(\frac{q E_{g}}{A K}\right)\left(\frac{1}{T_{\text {ref }}}-\frac{1}{T_{c}}\right)\right]
\end{aligned}
$$

where $I_{s c}$ is short circuit current, $V_{o c}$ is open circuit voltage, $T_{\text {ref }}$ is the temperature at STC and $E_{g}$ is cell material band gap energy.

The shunt resistance can be evaluated by the slope of $V-I$ curve at a short circuit and similarly the slope at open circuit can illustrate series resistance.

$$
\begin{gathered}
R_{s h}=-\frac{d V}{d I} \\
R_{s}=-\frac{d V}{d I}-\frac{V_{T}}{I_{s c}}
\end{gathered}
$$

The resistances can be found from a datasheet of PV panel by directly inspecting slope angles of given IV curve. In addition, authors in [17], [18] suggested estimation techniques and computational algorithms for $R_{s}$ and $R_{s h}$. After these calculations efficiencies of maximum power point tracking and power conditioning unit are considered as illustrated in [15] for the final calculation of PV plant power generation. Lastly, PV generation profiles were analyzed along with the load profile and the HPP. AUES was modelled in DIGSilent Power Factory 2018 such that PV plants integration can be evaluated in terms of bus voltage magnitudes and equipment loading rate (Fig. 2).

Typical load flow analysis is carried out in different load conditions by using the highest power generation of a source. In an analysis of PV plant integration, its production is not constant but diurnal and nominal capacity can be delivered around midday mostly. Therefore, it is suitable to carry out load flow analysis in quasi-dynamic simulation mode such as
24 hour period with 1-hour steps. Finally, the optimal size of the PV plant, which could be built in Mongolian Western region to support AUES microgrid operation, was chosen based on results of quasi-dynamic simulation and generation profile.

\section{Simulation Results And Discussion}

Using solar radiation measurement data and parametric models, the hourly power generation of PV plants with 10 and $20 \mathrm{MW}$ capacities were calculated for monthly average days. Monthly average daily generation profiles of PV plants for four different months representing four seasons in Mongolia, are shown in Fig. 4 with the load profiles of corresponding months.

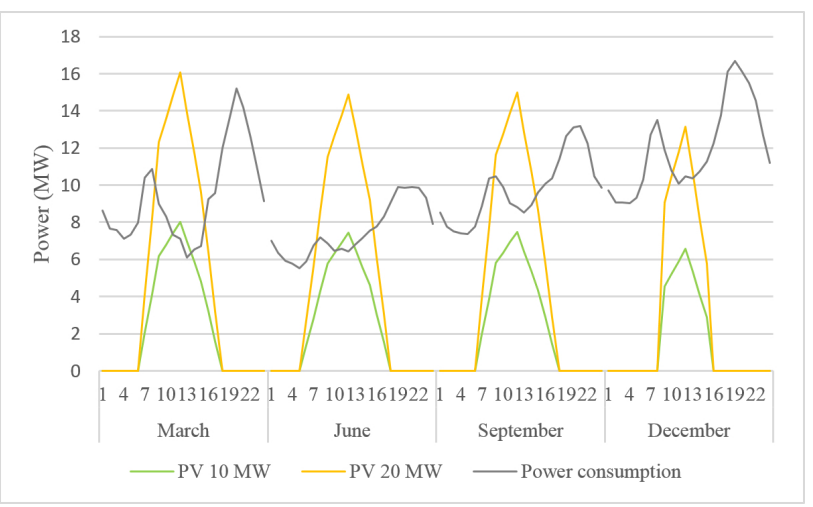

Fig. 4. PV plants generations and load profile of average days of corresponding months

As shown in Fig. 4, it is clear that $20 \mathrm{MW}$ PV plant generation well exceeded the load most of the year while 10 MW PV plant generation exceeded the load slightly on March and June. For $20 \mathrm{MW}$ PV case, the surplus energy could be injected into other networks. However, in an islanded operation it will be lost without storage system.

Since PV plant generation is the highest during March because of appropriate solar altitude and ambient temperature, it is interesting to see actual generations of PV plants rather than the average generation for this month. Actual three days measurement of radiation on March 2007 was used for creating the real generation profile, which is illustrated in Fig. 5.

Started working on 2010, AUES has Taishir 11 MW HPP, which has not worked on its nominal capacity due to the lack of water reservoir. The HPP can save water reservoir by means of PV plant and microgrid consists of these plants can work efficiently. Fig. 6 shows the hybrid-working scenario of the formed microgrid using current hydro generation, load and calculated PV generation.

The area of power consumption, which is not covered by microgrid production, is supplied by the central grid. The saved water during the daytime in an HPP due to the power generating of PV plant could be used to cover some part of the peak load. In addition, as shown in Fig. 6, it is obvious that microgrid does not have enough generation to fully supply its 


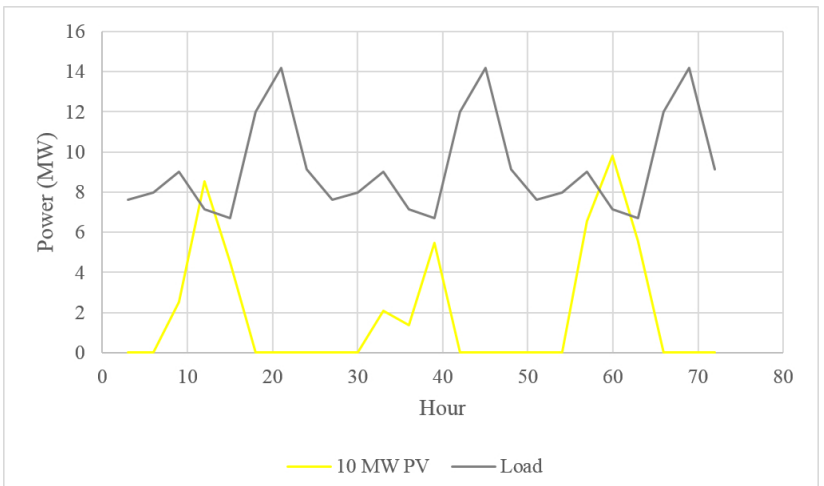

Fig. 5. Actual three days PV generation calculated from measurement data with a load curve

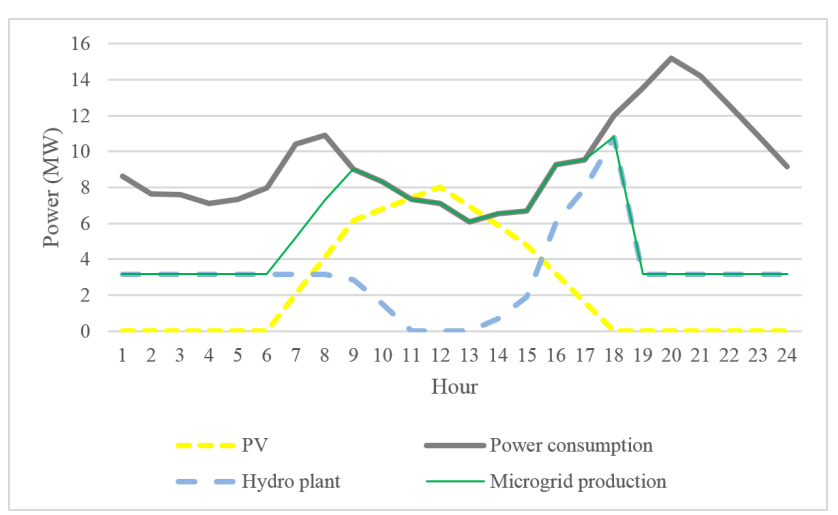

Fig. 6. Working scenario of proposed microgrid including PV and HPP with grid

loads if it works in islanded mode but prioritized loads could be supplied. Even if HPP accumulated full water reservoir, peak demand is higher than the nominal capacity of HPP and it requires more energy from the central grid.

The quasi-dynamic simulation was carried out in AUES in order to investigate PV plant integration scenarios. A simplified radial network of AUES shown in Fig. 2 was used in the simulation. The solar radiation measurement values and load profiles used in Fig. 5 were also used for the simulations since PV generation is highest in March. The software created PV generations automatically for different capacities of PV plants using the radiation data. Voltage magnitudes of all buses are in approved range except PV plant bus, which experiences slightly higher voltage during midday in both integration cases. A $10 \mathrm{MW}$ PV plant generation and an HPP generation during quasi-dynamic simulation were shown in Fig. 7 and correspondent bus voltages were shown in Fig. 8.

As Fig. 7 and Fig. 8 show, slight overvoltage has been observed on PV bus during peak generation period of PV plant. This increase was also influenced Bus 5 and 6 bus directly but the increase is in the normal range. Because of variable nature of PV plant, the buses do not experience overvoltage for a long time. Some results of the quasi-dynamic simulation

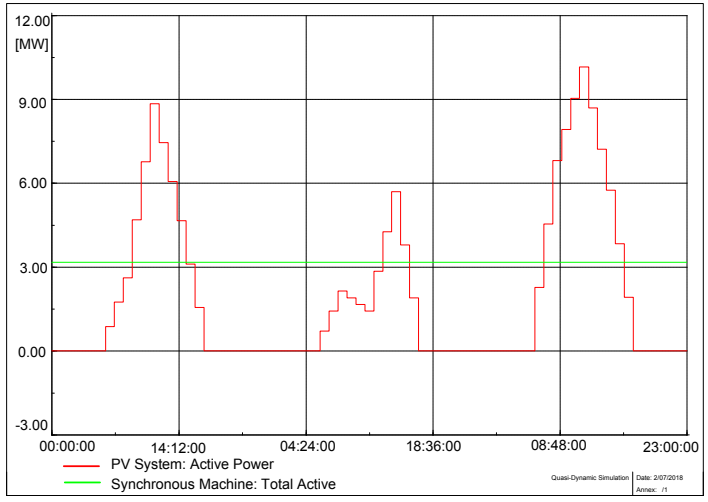

Fig. 7. Generations of the $10 \mathrm{MW}$ PV and the HPP modeled in DIGSilent

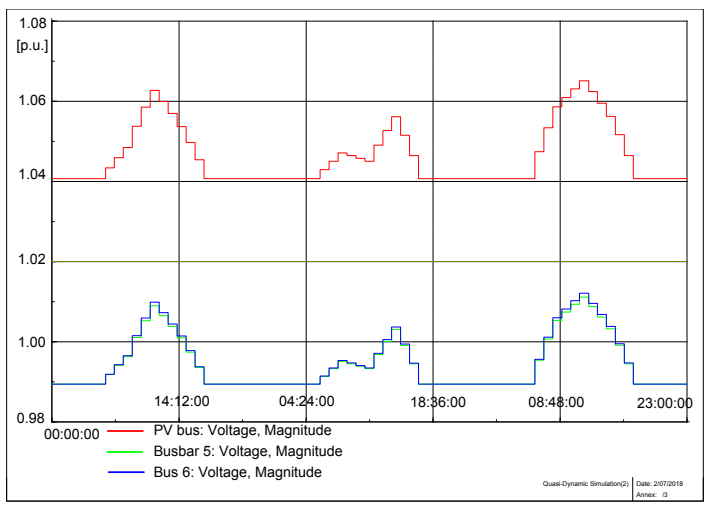

Fig. 8. Voltage magnitudes of Bus 5 and 6 during the $10 \mathrm{MW}$ PV integration

of the highest capacity scenario of PV plant integration were presented in Fig. 9 and Fig. 10.

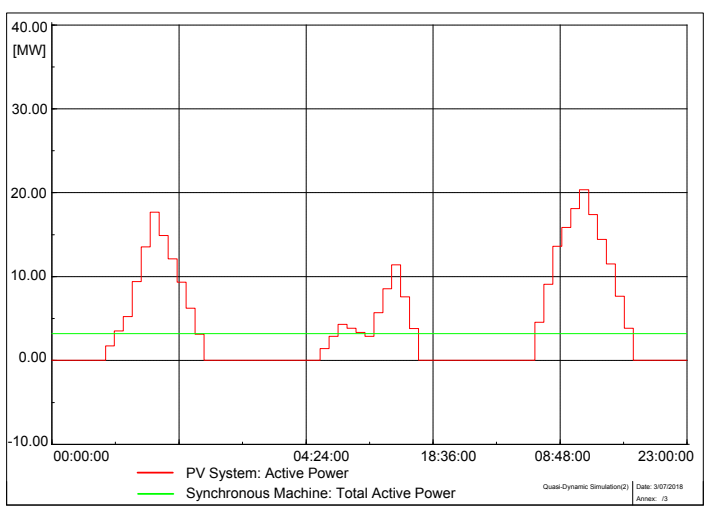

Fig. 9. Generations of the $20 \mathrm{MW} \mathrm{PV}$ and the HPP modeled in DIGSilent after quasi-dynamic simulation

From the graphs, we can see that principle of high voltage at PV bus is the same with $10 \mathrm{MW}$ PV plant case despite having higher numbers in magnitude. Since AUES is connected to the central grid and the grid connection was modelled on DIGsilent. The exceeded generation of the PV plant is exported to the central grid so that PV bus voltage was not too high. 


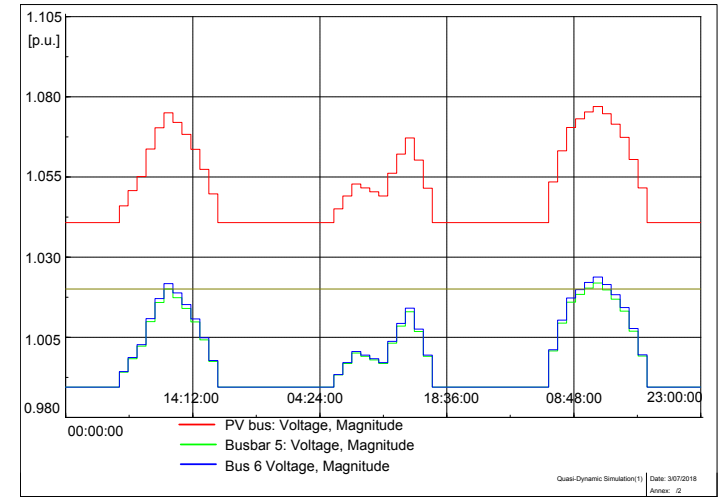

Fig. 10. Voltage magnitudes of Bus 5 and 6 during the 20 MW PV integration

This study has shown that $10 \mathrm{MW}$ PV plant is an effective choice for creating the microgrid in AUES in terms of energy production regardless of having minor overvoltage since higher capacity producing much exceeded-energy. For the islanded operation, additional energy storage and an auxiliary synchronous generator are required to fully supply loads of AUES. From the results, the $10 \mathrm{MW}$ PV plant will produce 14.15 million $\mathrm{kWh}$ electricity annually and reduce around 2.12 million $\mathrm{kWh}$ line loss by decreasing import from the central grid.

\section{CONCLUSION}

In this paper, the aim was to investigate the possibility of creating a microgrid in AUES of Mongolia by adding PV power plant into the network that currently has HPP. The PV plants integration scenarios with different capacities were examined in current AUES by using solar radiation measurement and load data. The results of the study show that the building PV plant in AUES is an effective way to create a resilient network in the region. Also, it can be seen that 10 MW PV plant size is the optimal choice for the system without considering an energy storage system. Moreover, a PV plant is an appropriate choice in terms of energy production point of view and exceeded PV generation could be supplied to the Western Energy Network of Mongolia. A PV plant generation will reduce HPP production significantly so that water reservoir could be saved and accumulated. If the water reservoir of the HPP gets full, the microgrid consists of the HPP and a PV plant could provide increasing demand of AUES in reliable and resilient manner. The reducing approaches for slight higher voltage of PV plant bus during the peak PV generation should be studied along with a battery storage and auxiliary generations possibilities for the microgrid of AUES.

\section{ACKNOWLEDGMENT}

The authors acknowledge support to carry out this research from Ministry of Foreign Affairs and Trade NZ Aid Scholarship; University of Auckland under Faculty Research Development Fund (FRDF) Grant 370953; and, New Zealand's Centre of Research Excellence Te Punaha Matatini.

\section{REFERENCES}

[1] M.J. Sanjari and G.B. Gharehpetian, "Unified framework for frequency and voltage control of autonomous microgrids," IET Generation, Transmission \& Distribution, 2013. 7(9): p. 965-972.

[2] REN21, 2017, Renewables 2017 Global Status Report, (Paris: REN21 Secretariat).

[3] R. H. Lasseter, "Control of distributed resources", Proc. Bulk Power System and Controls IV Conf., pp. 323-330, 1998.

[4] G. Venkataramanan, C. Marnay, "A larger role for microgrids", IEEE Power Energy Mag., vol. 6, no. 3, pp. 78-82, May/Jun. 2008.

[5] S. Bacha, D. Picault, B. Burger, I. Etxeberria-Otadui, J. Martins, "Photovoltaics in microgrids: An overview of grid integration and energy management aspects", IEEE Ind. Electron. Mag., vol. 9, no. 1, pp. 33-46, Mar. 2015.

[6] R. Shah, N. Mithulananthan, R. C. Bansal, and V. K. Ramachandaramurthy, "A review of key power system stability challenges for largescale PV integration," Renewable and Sustainable Energy Reviews, Review vol. 41, pp. 1423-1436, 2015.

[7] M. A. Eltawil and Z. Zhao, "Grid-connected photovoltaic power systems: Technical and potential problems-A review," Renewable and Sustainable Energy Reviews, Review vol. 14, no. 1, pp. 112-129, 2010.

[8] L. Gonzlez-Sotres, P. Fras, and C. Mateo, "Techno-economic assessment of forecasting and communication on centralized voltage control with high PV penetration," Electric Power Systems Research, Article vol. 151, pp. 338-347, 2017.

[9] R. Passey, T. Spooner, I. MacGill, M. Watt, and K. Syngellakis, "The potential impacts of grid-connected distributed generation and how to address them: A review of technical and non-technical factors," Energy Policy, Article vol. 39, no. 10, pp. 6280-6290, 2011.

[10] C. Lupangu and R. C. Bansal, "A review of technical issues on the development of solar photovoltaic systems," Renewable and Sustainable Energy Reviews, vol. 73, no. Supplement C, pp. 950-965, 2017/06/01/ 2017.

[11] IRENA, "Renewables Readiness Assessment: Mongolia," International Renewable Energy Agency2016.

[12] Mongolian Parliament, "State policy on Energy, Mongolia," ed, 2015.

[13] S. Gantumur and G. Bekhbat, "Challenges of hybrid DGs for islanded micro-grid operation in west region energy system of Mongolia," 2016 11 th International Forum on Strategic Technology (IFOST), Novosibirsk, 2016, pp. 237-242.

[14] J. A. Duffie and W. A. Beckman, "Solar Energy Thermal Processes", Fourth edition, Wiley, New York., 2013.

[15] D. R. Clark, S. A. Klein, and W. A. Beckman, "A method for estimating the performance of photovoltaic systems," Solar Energy, vol. 33, pp. 551-555, 1984/01/01/ 1984.

[16] M. G. Villalva, J. R. Gazoli and E. R. Filho, "Comprehensive Approach to Modeling and Simulation of Photovoltaic Arrays," in IEEE Transactions on Power Electronics, vol. 24, no. 5, pp. 1198-1208, May 2009.

[17] H. Bellia, R. Youcef, and M. Fatima, "A detailed modeling of photovoltaic module using MATLAB," NRIAG Journal of Astronomy and Geophysics, vol. 3, pp. 53-61, 2014/06/01/ 2014.

[18] H. G. Navada, S. V. Singh, and K. N. Shubhanga, "Modelling of a solar photovoltaic power plant for power system studies," in 2017 IEEE International Conference on Signal Processing, Informatics, Communication and Energy Systems (SPICES), 2017, pp. 1-6. 